\title{
Type A-Type B behavior and daily milk consumption in college students
}

\author{
ROBERT A. HICKS and WENDY GAUS \\ San Jose State University, San Jose, California
}

\begin{abstract}
A comparison of the daily milk consumption of students demonstrating Type A and Type B behavior patterns was performed as an indication of their daily calcium intake. Results indicate that Type As ingest an average of $35 \%$ less milk per day than do Type Bs. A link between Type As' reduced calcium intake and increased incidence of hypertension and coronary disease is suggested.
\end{abstract}

Recently, McCarron, Morris, and Cole (1982) observed that a group of normotensive adults (mean age $=39$ years) reported significantly greater (specifically, 33\% more) daily calcium ingestion than did a group of hypertensive adults (mean age $=42$ years). They concluded that their "data suggest that inadequate calcium intake may be a previously unrecognized factor in the development of hypertension" (p. 267).

Since there is a link between Type A behavior and hypertension that has not been adequately articulated (e.g., see Glass, 1977, and Williams, Lane, Kuhn, Melosh, White, \& Schanberg, 1982), we felt that it would be of interest to determine whether there were dietary differences between Type A and Type B college freshmen that would indicate possible differences in daily calcium intake, which McCarron et al. (1982) suggested may be implicated in the development of hypertension.

\section{METHOD}

To do this, we tested a group of 171 students with the Glass (1977) college-student version of the Jenkins Activity Survey, which we used to measure Type A-Type B behavior. As a rough check on daily calcium intake, we asked these students to estimate the number of glasses of milk they drank each day and to list any other dairy products that they consumed on a daily basis. These items were embedded in a 24-item health-oriented questionnaire.

\section{RESULTS AND DISCUSSION}

Consistent with norms derived from previous samples of our students (Hicks \& Schretlen, 1981), we

This research was supported by NIH Grant RR08192-03. Send reprint requests to Robert A. Hicks, Department of Psychology, San Jose State University, San Jose, California 95192. found that 69 students were Type As, that is, produced Jenkins's scores $\geqslant 9$, and 102 were Type Bs, that is, produced Jenkins's scores $<9$. We computed the mean daily milk intake for each of these groups and found that the Type As (mean $=1.3 \pm 1.2$ glasses $/$ day) consumed significantly less milk than the Type Bs (mean $=1.8 \pm 1.4$ glasses/day) $[\mathrm{t}(169)=2.25, \mathrm{p}<.05]$. We also noted that the groups did not differ in the percentage of individuals in each group that reported using other dairy products on a daily basis, (75\% and $71 \%$, respectively). It is of interest to note that the Type B group reported consuming 35\% more milk than did the Type A group. This percentage is similar to the one reported by McCarron et al. (1982) for the difference in calcium ingestion between their adult normotensive and hypertensive groups.

At best, these data indicate possible differences in diet between relatively young Type $\mathbf{A}$ and Type $\mathrm{B}$ individuals that might be linked to the development of coronary heart disease. We hope that this interesting correlation will stimulate more extensive inquiry into Type A-Type B dietary differences.

\section{REFERENCES}

Glass, D. C. Behavior patterns, stress, and coronary disease. Hillsdale, N.J: Erlbaum, 1977.

Hicks, R. A., \& Schretlen, D. Changes in level of Type A behavior in college students over a four-year period. Psychological Reports, 1981, 49, 22.

McCarron, D. A., Morris, C. D., \& Cole, C. Dietary calcium in human hypertension. Science, 1982, 217, 267-269.

Williams, R. B., Lane, J. D., Kuhn, C. M., Melosh, W., White, A. D., \& Schanberg, S. M. Type A behavior and elevated physiological and neuroendocrine responses to cognitive tasks. Science, 1982, 218, 483-485.

(Manuscript received for publication May 21, 1983.) 